\title{
DỨBin
}

Technological University Dublin

ARROW@TU Dublin

2011-05-10

\section{A Parametric Analysis of Domestic Electricity Consumption Patterns in Ireland}

\author{
Fintan McLoughlin \\ Technological University Dublin, fintan.mcloughlin@tudublin.ie \\ Aidan Duffy \\ Technological University Dublin, aidan.duffy@tudublin.ie \\ Michael Conlon \\ Technological University Dublin, michael.conlon@tudublin.ie
}

Follow this and additional works at: https://arrow.tudublin.ie/dubencon2

Part of the Applied Mathematics Commons, and the Electrical and Computer Engineering Commons

\section{Recommended Citation}

McLoughlin, F., Duffy, A. \& Conlon, M.: A parametric analysis of domestic electricity consumption patterns in Ireland. Tenth International Conference on Environment and Electrical Engineering (EEIC); Conference Proceedings, Rome, Italy, 8-11 May.

This Conference Paper is brought to you for free and open access by the Dublin Energy Lab at ARROW@TU Dublin. It has been accepted for inclusion in Conference Papers by an authorized administrator of ARROW@TU Dublin. For more information, please contact arrow.admin@tudublin.ie, aisling.coyne@tudublin.ie, gerard.connolly@tudublin.ie.

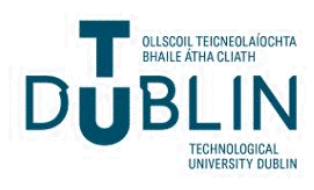




\section{A parametric analysis of domestic electricity consumption patterns in Ireland}

\author{
Fintan McLoughlin \\ School of Civil and Building \\ Services Engineering; and Dublin \\ Energy Lab, \\ Dublin Institute of Technology \\ Dublin, Ireland \\ fintan.mcloughlin@dit.ie
}

\author{
Aidan Duffy \\ School of Civil and Building \\ Services Engineering; and Dublin \\ Energy Lab, \\ Dublin Institute of Technology \\ Dublin, Ireland \\ aidan.duffy@dit.ie
}

\author{
Michael Conlon \\ School of Electrical Systems \\ Engineering; and Dublin Energy \\ Lab, \\ Dublin Institute of Technology \\ Dublin Ireland \\ michael.conlon@dit.ie
}

\begin{abstract}
This paper reports findings from a study of electrical load profiles obtained from a survey of a representative cross section of approximately 4,000 Irish dwellings. Electricity demand was recorded at half-hourly intervals for each dwelling over a six month period from 1st July 2009 to 31st December 2009. Descriptive statistics are shown for each electrical parameter such as mean, maximum demand, load factor and time of use (ToU) of electricity consumption. The mean power demand and daily mean load factor of the sample was $0.512 \mathrm{~kW}$ and $23.43 \%$ respectively for all dwellings over the monitoring period. A mean daily maximum demand of $2.5 \mathrm{~kW}$ was recorded for the sample. The most frequent ToU for maximum and minimum electricity consumption over the monitoring period was 18:00 - 18:30 and 06:30 - 07:00 respectively.
\end{abstract}

Keywords-component; domestic electricity consumption, load profiling

\section{INTRODUCTION}

Domestic electricity consumption in EU-27 countries accounted for $28.1 \%$ of final electricity demand in 2007 [1]. In Ireland, $32 \%$ of final electricity was consumed in the residential sector in 2009 [2]. This is the second largest electricity consuming sector in the economy, exceeded only by the industry sector. EU-27 energy-related greenhouse gas emissions (GHG) targets for 2020 (based on a 2005 emissions baseline) include a reduction of $21 \%$ in GHG emissions for the emission trading sector across the EU-27 countries and a $10 \%$ reduction for the non-trading sector across the EU. The $10 \%$ reduction across the EU-27 countries for the non-trading sector is broken up collectively for the different member states. Ireland has been assigned a target of $20 \%$ reduction in GHG emissions by 2020 [3].

The electricity industry within the EU is currently going through a period of transition, in an attempt to meet EU 2020 targets. The industry is gradually reducing its dependence on high carbon intensive fossil fuels and moving over to a less carbon intense fuels such as nuclear power and renewable energy. New technologies are helping to drive this change with large scale renewable energy (mostly consisting of wind power) providing $7.7 \%$ of energy input in 2009 to generate electricity in Ireland [2]. In the future, other technologies such as micro-generation and electric vehicles may also have a significant role to play in reducing Ireland's GHG emissions. In 2008, the Irish government announced a target of $10 \%$ of the national transport fleet to be powered by electric vehicles by 2020. Similarly, a feed in tariff was also introduced for Ireland for the first time in 2009, offering a tariff of $19 \mathrm{cent} / \mathrm{kWh}$ for micro-generation projects. Other operational measures such as demand side management and time of use (ToU) tariffs offer opportunities in the future to shift demand away from peak times resulting in a more efficient and hence less carbon intensive electricity sector.

However, in order to effectively assess the impact of such policy and technological changes discussed above there is a need to have an understanding of current customer electricity consumption patterns. In July 2009, the largest electricity supplier in the state - the Electricity Supply Board (ESB) commenced an 18 month smart metering survey of the domestic sector and small-to-medium enterprises (SME). The survey consisted of metering approximately 5,000 electricity customers at half hourly intervals as well as recording socioeconomic, demographic and dwelling characteristics for each household.

The survey is contributing to ESB's smart grid strategy for achieving high levels of wind power penetration onto its electricity network. However, in addition, the advantages of collecting such a detailed data set enable other groups such as policy makers to determine the impact of increased renewable energy penetration on GHG emissions and electrical grid infrastructure leading to optimal solutions for reducing emissions for the country.

The purpose of this paper is to characterise domestic electricity consumption in terms of parameters such as maximum demand, load factor, and ToU. These parameters can then be applied to simulate domestic electricity load 
profiles through various methods such as a Monte Carlo analysis. The parametric results are presented in this paper.

\section{METHODOLOGY}

Domestic electricity load profiles for individual dwellings are highly variable with typical consumption patterns often changing considerably across a twenty-four hour period. A typical daily load profile is shown in Fig. 1 below. Electricity consumption varies as a function of time and is influenced by various factors. A daily pattern is usually apparent, with a peak in the morning and evening times. For a given dwelling, electricity consumption peaks roughly occur at the same time of day and are strongly influenced by occupancy and activity patterns within a particular household [4].

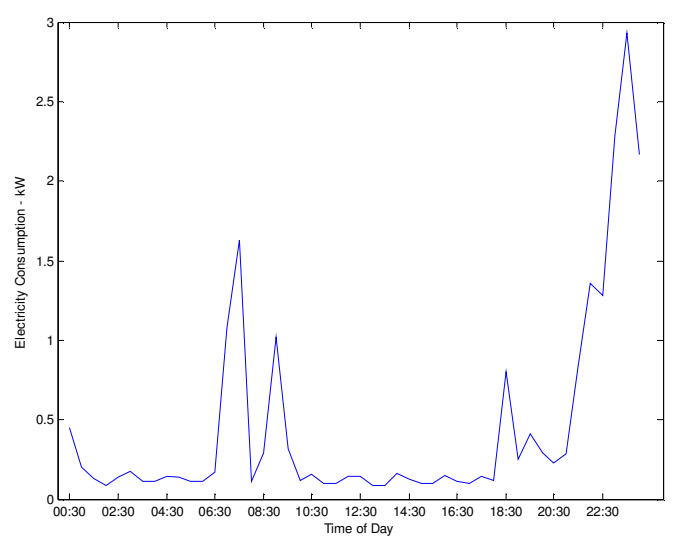

Figure 1. Electricity load profile for an individual dwelling across a $24 \mathrm{hr}$ period

A number of electrical parameters are presented below to characterise domestic electricity load profiles over a daily and a six month period. A descriptive statistics methodological approach is taken by investigating each electrical parameter by mean, median, standard deviation, maximum and minimum values. Probability distribution functions are fitted to each electrical parameter and distribution parameters presented.

The data set used in the analysis was taken from a population of 345,645 households. The population was divided into six categories based on total electricity consumption for each customer to ensure an even spread of electricity consuming customers. An initial sample of 5,574 was drawn on a randomised basis across all categories. This was subsequently reduced to 5,375 by targeting certain groups to improve representivity of dwelling and socio-economic variables within the sample size. The sample was further reduced to just less than 4,000 households for the analysis when non-continuous data, a result of communication errors, and SME's were removed from the data set. Anonymised half hourly electricity consumption data was recorded over a six month period from 1st July 2009 to 31st December 2009. The electrical parameters presented are:
- Mean Electricity Consumption

- Maximum Demand over Six Months

- Maximum Demand over a Day

- Load Factor over Six Months (max)

- Load Factor over a Day (max)

- Load Factor over Six Months (min)

- Load Factor over a Day (min)

- Maximum ToU

- Minimum ToU

Mean electricity consumption, $\mathrm{E}_{\mathrm{MEAN}}$ is calculated to determine average customer demand over a six month period (1) where i represents each half hourly interval and $n$ is the total number of intervals over the period.

$$
E_{\text {MEAN }}=\frac{1}{n} \cdot \sum_{i=1}^{n} E_{i}
$$

Maximum demand is calculated to determine peak electricity consumption for individual load profiles and is defined over two periods, six month maximum demand and daily maximum demand. Six month maximum demand is shown in (2) where $\mathrm{MD}_{\mathrm{SM}}$ is the maximum value of electricity consumed over the period, i represents each half hourly interval and $\mathrm{n}$ is the total number of intervals over the six month period.

$$
M D_{S M}=\text { Maximum }\left(\sum_{i=1}^{n} E_{i}\right)
$$

Equation (3) describes mean daily maximum demand over the six month period, $\mathrm{MD}_{\mathrm{DAILY}}$, where i represents each half hourly interval in a single day, $\mathrm{n}$ is the total number of intervals in a day, $\mathrm{j}$ represents each day and $\mathrm{m}$ is the total number of days for the six month period.

$$
M D_{D A I L Y}=\frac{1}{m} \sum_{j=1}^{m} \operatorname{Maximum}\left(\sum_{i=1}^{n} E_{i}\right)
$$

Load factor gives an indication of the 'peakiness' of individual customer load profiles. Load factor is defined over two time periods, six month load factor and daily load factor. Maximum and minimum load factors are defined separately. Equation (4) describes six month maximum load factor, $\mathrm{LF}_{\mathrm{SM}}$ (MAX), which is the mean value of electricity consumption divided by the maximum value for each customer.

$$
L F_{S M(M A X)}=\frac{\operatorname{Mean}\left(\sum_{i=1}^{n} E_{i}\right)}{\operatorname{Maximum}\left(\sum_{i=1}^{n} E_{i}\right)}
$$


Daily maximum load factor, $\mathrm{LF}_{\text {DAILY (MAX) }}$ is defined by (5) where $\mathrm{i}$ represents each half hourly interval in a single day, $\mathrm{n}$ is the total number of intervals in a day, $\mathrm{j}$ represents each day and $\mathrm{m}$ is the total number of days for the six month period.

$$
L F_{D A I L Y(M A X)}=\frac{1}{m} \cdot \sum_{j=1}^{m}\left(\sum_{i=1}^{n} \frac{\operatorname{Mean}\left(E_{i}\right)}{\operatorname{Maximum}\left(E_{i}\right)}\right)
$$

Equation (6) defines six month minimum load factor, $\mathrm{LF}_{\mathrm{SM}}$ (MIN), which is the minimum value of electricity consumption divided by the mean value for each customer.

$$
\operatorname{LFSM}(\operatorname{MIN})=\operatorname{Minimum}\left(\sum_{i=1}^{n} E_{i}\right) / \operatorname{Mean}\left(\sum_{i=1}^{n} E_{i}\right)
$$

Daily minimum load factor, $\mathrm{LF}_{\mathrm{DAILY}(\mathrm{MIN})}$ is defined by (7) where $\mathrm{i}$ represents each half hourly interval in a single day, $\mathrm{n}$ is the total number of intervals in a day, $\mathrm{j}$ represents each day and $\mathrm{m}$ is the total number of days for the six month period.

$$
L F_{D A I L Y(M I N)}=\frac{1}{m} \sum_{j=1}^{m}\left(\sum_{i=1}^{n} \frac{\operatorname{Minimum}\left(E_{i}\right)}{\operatorname{Mean}\left(E_{i}\right)}\right)
$$

A ToU parameter is defined over a six month period which represents the timing of individual customer's maximum and minimum electricity demand. A maximum time of use (ToU)

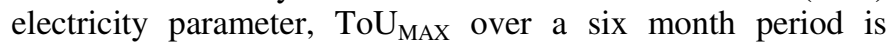
shown in (8) where $i$ represents each half hourly interval in a single day, $\mathrm{n}$ is the total number of intervals in a day, $\mathrm{T}$ is the time of day at which the maximum occurs, $j$ represents each day and $\mathrm{m}$ is the total number of days for the six month period.

$$
\operatorname{ToU}_{\text {MAX }}=\operatorname{Mode}\left(\sum_{j=1}^{m} T_{j}\left(\operatorname{Maximum}\left(\sum_{i=1}^{n} E_{i}\right)\right)\right)
$$

Similarly a minimum ToU of use electricity parameter is defined in (9).

$$
\operatorname{ToU}_{\text {MIN }}=\operatorname{Mode}\left(\sum_{j=1}^{m} T_{j}\left(\operatorname{Minimum}\left(\sum_{i=1}^{n} E_{i}\right)\right)\right)
$$

\section{RESULTS AND DISCUSSION}

Descriptive statistics such as mean, median, standard deviation, maximum and minimum values are calculated for each electrical parameters above in equations 1-7, and are shown in Table I below.
TABLE I. DESCRPTIVE STATISTICS FOR EACH ELECTRICAL PARAMETER

\begin{tabular}{|l|l|c|c|c|c|}
\hline \multirow{2}{*}{} & \multicolumn{5}{|c|}{ Descriptive Statistics } \\
\cline { 2 - 6 } & \multicolumn{1}{|c|}{ Mean } & Median & STD & Max & Min \\
\hline $\mathrm{E}_{\mathrm{MEAN}}(\mathrm{kW})$ & 0.51 & 0.50 & 0.24 & 14.16 & 0.00 \\
\hline $\mathrm{MD}_{\mathrm{SM}}(\mathrm{kW})$ & 5.90 & 5.75 & 2.01 & 14.16 & 0.44 \\
\hline $\mathrm{MD}_{\mathrm{DAILY}}(\mathrm{kW})$ & 2.50 & 2.49 & 1.01 & 7.36 & 0.07 \\
\hline $\mathrm{LF}_{\mathrm{SM}(\max )}(\%)$ & 8.68 & 8.46 & 3.08 & 29.99 & 0.77 \\
\hline $\mathrm{LF}_{\mathrm{DAILY}(\max )}(\%)$ & 23.43 & 22.53 & 6.33 & 82.00 & 8.13 \\
\hline $\mathrm{LF}_{\mathrm{SM}(\min )}(\%)$ & 9.71 & 8.01 & 7.14 & 52.53 & 0.15 \\
\hline $\mathrm{LF}_{\mathrm{DAILY}(\min )}(\%)$ & 21.10 & 19.47 & 10.93 & 89.80 & 0 \\
\hline
\end{tabular}

Load factor does not change significantly between different customers as indicated by a relatively low standard deviation. Daily maximum demand ( $\left.\mathrm{MD}_{\mathrm{DAILY}}\right)$ is approximately half of six month maximum demand $\left(\mathrm{MD}_{\mathrm{SM}}\right)$ indicating the level of diversity for individual customers.

Maximum and minimum ToU parameters are shown in Table II below.

TABLE II. DESCRPTIVE STATISTICS FOR TOU PARAMETER

\begin{tabular}{|l|c|c|}
\hline \multirow{2}{*}{} & \multicolumn{2}{|c|}{ Descriptive Statistics (Time) } \\
\cline { 2 - 3 } & Maximum & Minimum \\
\hline ToU $_{\text {MAX }}$ & $18: 00-18: 30$ & $03: 00-03: 30$ \\
\hline ToU $_{\text {MIN }}$ & $06: 30-07: 00$ & $20: 30-21: 00$ \\
\hline
\end{tabular}

Fig. 2 shows maximum ToU use parameter across the day. The results are based on most frequent ToU values over the six month period and will change slightly due to seasonality. Three clear peaks are evident with one in the morning between 08:00-08:30, a smaller peak at lunch time between 13:30-14:00 and a larger peak in the evening time between 18:00 and 18:30.

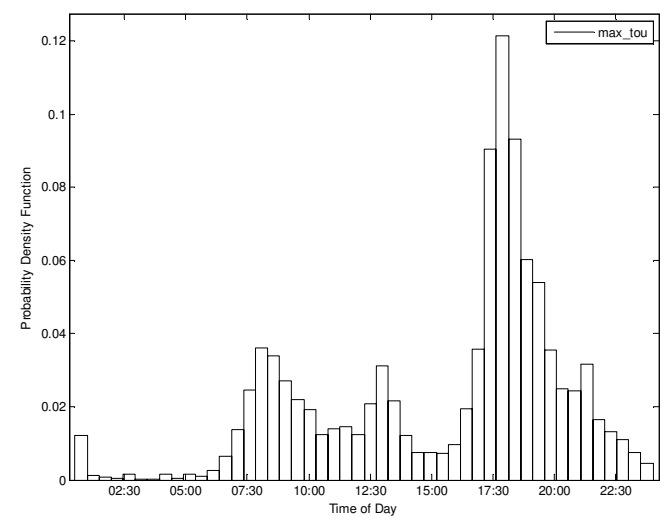

Figure 2. Maximum ToU across 24 hour period

Minimum electricity consumption ToU is shown in Fig. 3. The most frequent minimum value for electricity consumption occurs between 06:30 - 07:00 which is unusual but in general 
represents the time between night time devices switching off and increased morning activity of occupants.

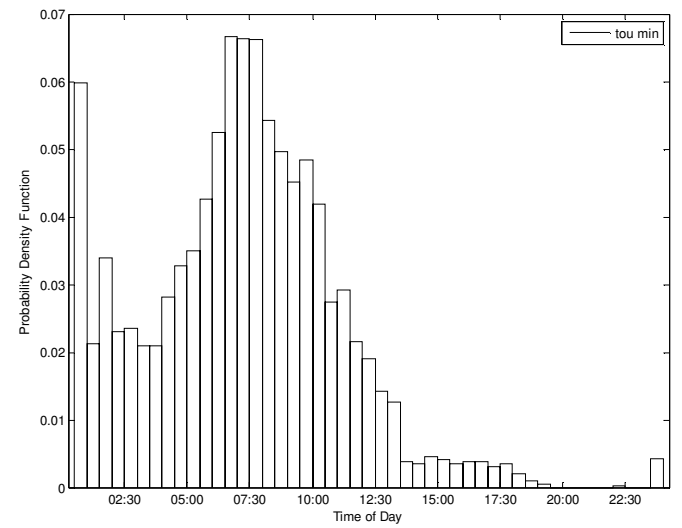

Figure 3. Minimum ToU across 24 hour period

Probability distribution functions are fitted to each electrical parameter and distribution variables are shown in Table III below.

TABLE III. PROBABILITY DISTRIBUTION PARAMETERS FOR EACH ELECTRICAL PARAMETER

\begin{tabular}{|l|l|c|}
\hline \multirow{2}{*}{} & \multicolumn{2}{|c|}{ Descriptive Statistics } \\
\cline { 2 - 3 } & $\begin{array}{c}\text { Probability Distribution } \\
\text { Scale Parameter }\end{array}$ & $\begin{array}{c}\text { Probability Distribution } \\
\text { Shape Parameter }\end{array}$ \\
\hline $\mathrm{E}_{\mathrm{MEAN}}$ & 0.58 & 2.15 \\
\hline $\mathrm{MD}_{\mathrm{SM}}$ & 6.58 & 6.17 \\
\hline $\mathrm{MD}_{\mathrm{DAILY}}$ & 2.81 & 2.65 \\
\hline $\mathrm{LF}_{\mathrm{SM}(\max )}$ & 0.10 & 2.96 \\
\hline $\begin{array}{l}\mathrm{LF}_{\mathrm{DAILY}} \\
(\max )\end{array}$ & $0.14^{*}$ & $-1.49^{*}$ \\
\hline $\mathrm{LF}_{\mathrm{SM}(\min )}$ & 0.11 & 1.42 \\
\hline $\begin{array}{l}\mathrm{LF}_{\mathrm{DAILY}} \\
(\min )\end{array}$ & $0.06^{* *}$ & $0.20^{* * *}$ \\
\hline
\end{tabular}

Weibull Probability Distribution Function

$$
f(T)=\frac{\beta}{\eta}\left(\frac{T}{\eta}\right)^{\beta-1} e^{-\left(\frac{T}{\eta}\right)^{\beta}}
$$

* Log-Logistic Probability Distribution Function

$$
\begin{array}{r}
f(T)=\frac{e^{z}}{\sigma T\left(1+e^{z}\right)^{2}} ; \quad z=\frac{T^{\prime}-\mu}{\sigma} ; T^{\prime}=\ln (T) \\
\text { ** Logistic Probability Distribution Function } \\
f(t)=\frac{e^{z}}{\sigma\left(1+e^{z}\right)^{2}} ; \quad z=\frac{t-\mu}{\sigma}
\end{array}
$$

\section{CONCLUSIONS}

Results for electrical parameters are presented from a survey of approximately 4,000 dwellings in Ireland over a six month period. Mean daily maximum demand was shown to be approximately half of maximum demand over six month period. Similarly, maximum and minimum load factors over six months are slightly less than half daily load factors over an average day. Maximum ToU shows three peaks throughout the day corresponding to morning, lunch and evening peaks. Minimum ToU shows a peak early morning reflecting the period just before normal morning activity from occupants.

\section{ACKNOWLEDGMENT}

Dublin Institute of Technology would like to acknowledge the support of the Electricity Supply Board of Ireland for access to the dataset.

\section{REFERENCES}

[1] European Environment Agency, Final electricity consumption by sector (ENER 018) - Assessment, 2010, (accessed 18/01/2011). http://www.eea.europa.eu/data-and-maps/indicators/final-electricityconsumption-by-sector/final-electricity-consumption-by-sector-1

[2] Sustainable Energy Authority of Ireland (SEAI), Energy in Ireland 1990-2009, 2010.

[3] Environment Protection Agency (EPA), Ireland's greenhouse gas emissions in 2009, 2010.

[4] Yohanis, Y. G., Mondol, J.D., Wright, A., Norton, B., "Real-life energy use in the UK: How occupancy and dwelling characteristics affect domestic electricity use." Energy and Buildings (2008) 40(6): 10531059. 